BILDERMAN, (i, B. Iorgetting of an operant response: lhysostigmine-produced amnesia in rats as a function of time of injection. Quarterly Journal of Experinental Psychology, 1970. in press.

DEUTSCH, J. A., HAMBURG, M. D.. \& DAHL, $H$. Anticholinesterase-induced amnesia and its temporal aspects. Science, 1966, 151, $221-223$.

DEUTSCH, J. A., \& LEIBOWITZ, S. F. Amnesia or reversal of forgetting by anticholinesterase, depending simply on time of injection. Science, 1966, 153, 1017-1018.

DEUTSCH, J. A., \& LUTZKY, H. Memory enhancement of anticholinesterase as a function of initial learning. Nature, 1967, 213, 742 .

DEUTSCH, J. A., \& WIENER, N. Effect of reinforcement and non-reinforcement on anticholinesterase-induced amnesia. Paper presented at American Psychological Association, 1968.

HAMBURG, M. D. Retrograde amnesia produced by intraperitoneal injection of physostigmine. Science, 1967, 156, 973-974.

VAlLLANT, G. E. Antagonism between physostigmine and atropine on the behavior of the pigcon. Archiv fur Pharmakologie und Ixpcrimentelle Pathologic, 1964, 248, 406-416.

VAILLANT, G. E. A comparison of antagonists of physostigmine-induced suppression of behavior. Journal of Pharmacology \& Experimental Therapeutics, 1967, 157 , 636-648.

WIENER, N., \& DEUTSCH, J. A. Temporal aspects of anticholinergic- and anticholinesterase-induced amnesia for an appetitive habit. Journal of Comparative \& Physiological Psychology, 1968, 66, 613-617.

\title{
Strain differences in morphine-withdrawal-induced aggression in rats*
}

\section{LOWELL A. BORGEN, J. H. KHALSA, WILLIAM T. KING, and W. MARVIN DAVIS University of Mississippi School of Pharmacy, University, Miss. 38677}

Male rats (housed six/cage) of three strains-Sprague-Dawley, Wistar, and Long-Evans-were given IP injections of morphine sulfate in dosages increasing over a 15-day period to a terminal dose of $405 \mathrm{mg} / \mathrm{kg} /$ day. Groups of six from each strain received saline control injections. Approximately $50 \mathrm{~h}$ after the last injection, significant increases in fighting behavior were observed in the Long-Evans and Wistar strains, the Long-Evans rats showing the most aggression. The fighting continued for about $40 \mathrm{~h}$ and then subsided to control levels. The Sprague-Dawley rats receiving morphine showed no significant increase in aggressiveness over placebo-injected animals.

Several investigations have shown that the withdrawal of morphine from physically dependent rats leads to the occurrence of fighting behavior in male Sprague-Dawley rats (Boshka, Weisman, \& Thor, 1966: Thor \& Teel, 1968) and Long.Evans rats (Thor, Hoats, \& Thor, 1970). These authors found that the fighting behavior began about 60 to $75 \mathrm{~h}$ after withdrawal from morphine, continued for 50 to $60 \mathrm{~h}$, then subsided to negligible levels. The present study was intended in part to replicate these previous studies and also to determine whether or not the occurrence of this response might

*This work was supported by USPHS Grant MH 11295-04. differ between the three most commonly used strains-the Sprague-Dawley, Wistar, and Long-Evans rats.

\section{SUBJECTS}

Thirty-six male rats of each of the three strains were used. ${ }^{1}$ The Ss were 47.57 days of age and weighed $220-280 \mathrm{~g}$ at the start of the experiments. They were housed in groups of six, with four groups of each strain being experimentals and two groups serving as controls. The cages measured $13 \frac{1}{2}$ in. wide $\times 22$ in. deep $\times 9 \frac{1}{2}$ in. high. Food and water were available ad lib throughout the experiment. Animals were ear-notched for identification and assigned randomly to groups. Prior to and throughout the experiment, the animals were maintained on a schedule of 16 h day
(0600 to 2200) and $8 \mathrm{~h}$ night. The observation rooms were illuminated by a 60-W red light at night to facilitate observation during the withdrawal period.

\section{PROCEDURE}

Experimental animals of each strain were injected with morphine sulfate over a 15-day period, starting with $15 \mathrm{mg} / \mathrm{kg} /$ day and increasing to a terminal dose of $405 \mathrm{mg} / \mathrm{kg} /$ day. All injections were made intraperitoneally, with equal doses being given at 6 a.m., 3 p.m., and 10 p.m. Drug solutions were prepared on the basis of weight of the sulfate salt, using $0.9 \% \mathrm{NaCl}$ in water as the vehicle. Placebo injections were of $0.9 \% \mathrm{NaCl}$ solution alone. A constant injection volume of $1 \mathrm{ml}$ solution $/ 200 \mathrm{~g}$ body weight was used throughout.

After the 15-day injection period, the Ss were observed for 15 -min periods every $2 \mathrm{~h}$ for 6 consecutive days. Six groups of rats (two of each strain) were observed at one time. An aggressive response was recorded only when at least two Ss assumed an upright fighting posture facing each other, and a biting attack with vocalization occurred. Experience revealed that true fighting behavior was easily distinguishable from playful "rough-housing," mounting, or grooming, although occasionally these behaviors would precipitate an actual biting attack by another animal. Because of the unique character of the fighting response, only one $\mathrm{O}$ was needed to watch the six cages during the 15 -min observation periods.

\section{RESULTS}

The cumulative fighting responses of all three strains of experimental and control animals are presented in Fig. 1. From the response curves it can be seen that the control groups from all strains displayed about the same amount of aggression over the 144-h observation period $(47,57$, and 71 responses). Curiously, the Sprague-Dawley morphine groups displayed only 50 aggressive responses during the withdrawal period. In contrast, the morphine-treated Wistar groups emitted 165 fighting responses, while the Long-Evans morphine groups showed some 460 aggressive episodes during the same interval. Figure 1 also shows that the bulk of the aggressive responses made by the Long-Evans and Wistar Ss occurred between 50 and $90 \mathrm{~h}$ after the last morphine injection.

During the withdrawal period two other behaviors indicative of an abstinence syndrome in the rat were noted. The first was a frequent shaking of the entire body, earlier described by other investigators as a "wet dog shake," and observed to be a concomitant of morphine withdrawal in 


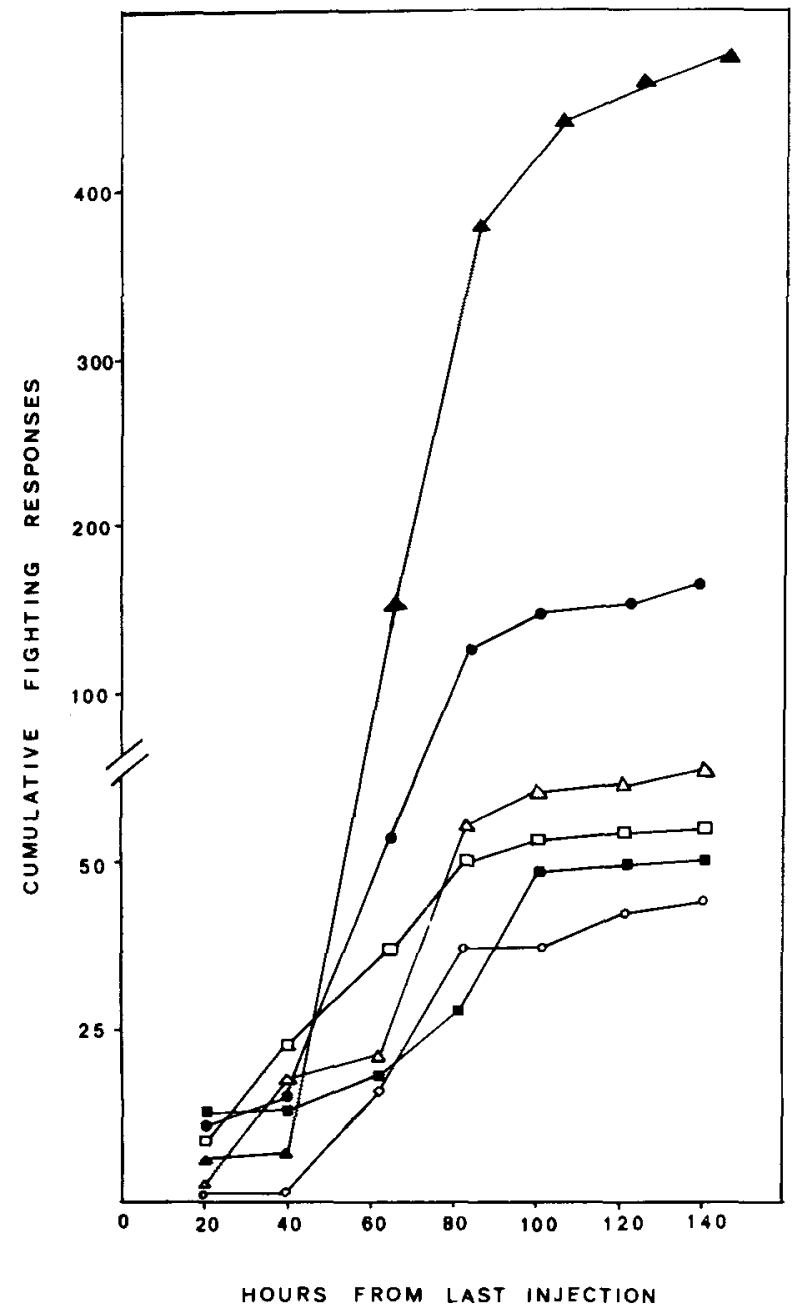

Fig. 1. Comparison of cumulative incidence of fighting episodes during morphine withdrawal for different rat strains. Triangles indicate Long-Evans strain, circles Wistar, and squares Sprague-Dawley. Filled data points indicate morphine-treated, open data points saline control groups.

rodents (Martin, Wikler, Eades, \& Pescor, 1963). The second behavior peculiar to the morphine-treated animals during withdrawal was a pronounced stretching movement and an apparent hind-leg weakness. Behavior similar to this (often termed "writhing") has been reported to occur when irritating, pain-producing materials are administered intraperitoneally to rats or mice (Vander Wende, \& Margolin, 1956; Siegmund, Cadmus, \& Lu, 1957). A qualitative notation of these two behaviors during the withdrawal observation period revealed that the frequency of the "wet dog shakes" and of the hind-leg stretching paralleled the occurrence of the aggressive behavior.

\section{DISCUSSION}

The present study provides additional evidence that the withdrawal from high doses of morphine sulfate is a noxious interoceptive stimulus capable of inducing fighting behavior among group-caged rats.
The character of the response (upright posture, biting attack, squealing) is quite distinctive and not at all difficult to differentiate from other behaviors. On several occasions during the peak of the aggressive activity, $S$ s were observed to remain in the upright posture nose-to-nose throughout the entire $15-\mathrm{min}$ observation period. The fighting response seems indistinguishable from the behavior described by others using exteroceptive aversive stimulation, such as electric shock (Ulrich \& Azrin, 1962).

The close parallelism of the three control curves indicates an absence of any difference between these three strains of rats in spontaneous aggressive behavior under these experimental conditions. The observation that the Sprague-Dawley strain did not exhibit significant aggression during morphine withdrawal is in sharp contrast to the report of Thor \& Teel (1968), who demonstrated extensive fighting behavior in this strain under similar experimental conditions. On the other hand, this study reveals that the Wistar and Long-Evans strains both display significant fighting during morphine withdrawal, with the Long-Evans being by far the most aggressive. Such activity was reported for the Long-Evans strain after the completion of our study (Thor, Hoats, \& Thor, 1970) but without a direct comparison to another strain. The present study also differs in that the peak of aggression occurred at 60 to $70 \mathrm{~h}$ in to the withdrawal period, compared to a maximum at 75 to $95 \mathrm{~h}$ or 85 to $100 \mathrm{~h}$, as found in previous investigations (Thor, Hoats, \& Thor, 1970; Thor \& Teel, 1968).

It also appears from this study that significant differences exist between genetic strains of rats in this aggressive response to morphine withdrawal. The reason for lack of aggression by the Sprague-Dawley rats in our study in contrast to other reports is not readily apparent. Some of the factors possibly playing an important role in eliciting this response may include (1) age of the Ss, (2) size of the group, (3) size of the cage. and (4) whether Ss were housed individually or in groups prior to the withdrawal period. Also, differences between animals of the same strain obtained from different breeders might occur. The influence of certain of these factors is presently being studied in attempting to resolve this question.

\section{REFERENCES}

BOSHKA, S. C., WEISMAN, H, M., \& THOR, D.

H. A technique for inducing aggression in rats utilizing morphine withdrawal. Psychological Record, 1966, 16, $541-543$.

MARTIN, W. R., WIKLER, A., EADES, C. G.. \& PESCOR, F. T. Tolerance to and physical dependence on morphine in rats. Psychopharmacologia, 1963. 4, 247-260.

SIEGMUND, E., CADMUS, R., \& LU, G. Method for evaluating both non-narcotic and narcotic analgesics. Proceedings of the Society for Experimental Biology and Medicine, 1957, 95, 729-731.

THOR, D. H., HOATS, D. L., \& THOR, C. J, Morphine-induced fighting and prior social experience. Psychonomic Science, 1970, 18, 137-139.

THOR, D. H., \& TEEL, B. G. Fighting of rats during post-morphine withdrawal: Effects of pre-withdrawal dosage. American Joumal of Psychology, 1968, 81, 439-442.

ULRICH, R. E, \& AZRIN, N. H. Reflexive fighting in response to aversive stimulation. Journal of the Experimental Analysis of Behavior, 1962, 5, 511-520.

VANDER WENDE, G., \& MARGOLIN, S. Analgesic tests based upon experimentally induced acute abdominal pain in rats. Federation Proceedings. 1956, 15, 494. NOTE

1. Sources: Sprague-Dawley rats, Holtzman Co. Madison, Wis.: Wistar rats, National Laboratory Animal Co., Creve .Coeur. Mo.; Long-Evans rats. Simonsen Laboratories, Gilroy, Calif. 